\title{
Representações das crianças sobre o brincar na escola
}

\author{
Míriam Stock Palma ${ }^{\mathrm{i}}$ \\ Universidade Federal do Rio Grande do Sul, Brasil
}

Resumo

O objetivo desta investigação foi compreender as representações das crianças sobre o brincar em diferentes espaços escolares, nomeadamente no recreio, na sala de aula e na aula de Educação Física. A partir da análise das entrevistas realizadas a 106 crianças, entre os 5 e os 12 anos de idade, numa escola da rede pública de Porto Alegre, Rio Grande do Sul, Brasil, verificouse que as brincadeiras prediletas são as que implicam movimento e ocorrem, em grupo, no espaço de recreio da escola. As crianças que frequentam o Jardim de Infância afirmam que brincam em sala de aula, enquanto as que frequentam o Ensino Fundamental declaram não brincar ou brincar pouco nesse espaço. Nas aulas de Educação Física elas realizam brincadeiras diversificadas, muitas das quais coincidem com as suas preferidas.

Palavras-chave

Infância; Brincadeiras; Educação

\section{Introdução e enquadramento}

A criança e a infância têm inspirado pesquisas em várias áreas de conhecimento ao longo do tempo, nomeadamente na área da Sociologia da Infância. A infância é concebida como categoria social do tipo geracional e a criança como um sujeito social ativo, capaz de produzir e reproduzir cultura nas interações que estabelece com os pares e com os adultos (Nascimento \& Souza, 2014; Sarmento, Fernandes, \& Tomás, 2007). As primeiras interações 
entre a criança e o outro são construídas, em princípio, no círculo familiar, mas, cada vez mais cedo, ela passa a fazer parte de outros universos de socialização, como a escola, a rua, a igreja, a mídia, o centro comunitário, etc. (Belloni, 2007; Sarmento, 2008; Valença, 2010). Através da observação cotidiana das atividades dos adultos e dos pares, bem como da sua participação efetiva nas rotinas desses distintos universos, a criança vai apreendendo as dinâmicas das realidades que a cercam, construindo conhecimentos e elaborando suas próprias formas de ler o mundo e de agir intencionalmente sobre ele. Assim, imersas em contextos sociais, desde os mais restritos - como, por exemplo, o familiar - até os mais amplos, as crianças, nas interações entre si e com os outros membros da sociedade, vão produzindo, compartilhando e ressignificando rituais, costumes, valores e brincadeiras, fazendo emergir uma cultura específica.

Mas se engana quem concebe as culturas da infância como homogêneas, universais; uma mesma informação ou situação adquire significações diferentes para cada criança, como resultado das suas experiências de vida, dos cenários sociais e culturais onde estabelece relações com os adultos e com os pares, de acordo ainda com sua condição econômica, gênero, etnia ou localização geográfica. Brincar de guerra, por exemplo, assume contornos bastante diferenciados para quem se aterroriza cotidianamente com os bombardeios reais "sobre suas cabeças"'" e para quem nunca vivenciou esse drama. No seio da cultura da infância, tão plural e heterogênea, desponta a centralidade da vida das crianças: o jogo e a brincadeira, os quais revelam, muitas vezes, as perceções que as crianças têm do mundo à sua volta, acrescidas de novos e singulares sentidos. Mais do que uma característica ou necessidade, o brincar é reconhecido como um direito social da criança (Brasil, 1990; UNICEF, 1959, 1989), influenciando positivamente o seu desenvolvimento e configurando-se como a expressão maior das culturas lúdicas da infância.

Inúmeros estudos têm evidenciado a necessidade de a ludicidade ser vivenciada e promovida como dimensão fundamental da formação humana, tanto nos contextos informais quanto formais, uma vez que, ao brincar, as crianças adquirem competências sociais e pessoais fundamentais para a sua vida cotidiana com repercussão ao longo da vida, (re)conhecem suas capacidades e limites, aprendem a superar-se, edificam suas estruturas 
mentais e emocionais, preparando-se para assumir o(s) seu(s) papel(éis) na sociedade (Kishimoto, 2010; Moyles, 2006; Sarmento, 2004; Silva, 2008).

O Comitê sobre os Direitos da Criança da Organização das Nações Unidas (2013) publicou o Comentário Geral sobre o artigo 31 da Convenção sobre os Direitos da Criança, visando alertar os Estados, o setor privado e todos os que trabalham com crianças para a necessidade de uma melhor e maior compreensão da importância de respeitar este artigo da Convenção, em especial o direito a brincar, uma vez que a brincadeira é uma componente vital para o seu desenvolvimento físico, social, cognitivo, emocional e espiritual. Entretanto, outras investigações referem que o tempo e os espaços em que as crianças podem brincar têm sido bastante reduzidos; de entre os motivos apontados, estão a falta de segurança nas cidades, nomeadamente pelo grande fluxo de transportes nas ruas, a vida atribulada das famílias, a exclusão das crianças dos espaços públicos, a pressão social para o sucesso educativo, o trabalho infantil, o excesso de atividades estruturadas no seu cotidiano, a escassez de investimentos em locais públicos que oportunizem jogos e brincadeiras para as crianças, bem como a falta de reconhecimento da importância do brincar na infância por parte dos adultos responsáveis, direta ou indiretamente, pela educação das crianças (Corsaro, 2011; Palma, Almeida, Turcati, \& Pontes, 2015; Sarmento \& Marchi, 2008; Silva, 2011).

Diante dessa realidade, Silva (2011) assinala a escola como o locus privilegiado para a constituição de sociedades infantis duradouras, em que ainda é possível juntar crianças a brincar e onde se perpetua a tradição infantil verdadeiramente democratizada. Cabe destacar que, na atualidade, boa parte do tempo diário das crianças é despendido no interior da escola, como consequência do grande envolvimento de pais e de mães com o trabalho, refletindo-se no pouco tempo que dedicam a estar e a brincar com seus filhos. Consideramos que tempo e espaço são condições essenciais para que o brincar emerja e se desenvolva e, no âmbito escolar, o recreio tem sido apontado como o tempo e o espaço de perpetuação e produção das culturas da infância e, de forma muito peculiar, das culturas lúdicas da infância. Considerado, por vezes, um espaço barulhento, pouco produtivo, de desordem, sem lógica, especialmente pelos adultos, o recreio se configura, segundo Nascimento e Souza (2014), Martins e Cruz (2014) e Azevedo (2014), como uma microssociedade, onde se pode identificar a organização 
das crianças em grupos, dentro dos quais aprendem a gerir as relações humanas em uma igualdade de status que não existe numa relação entre crianças e adultos, assumindo diferentes papéis e compartilhando sentimentos como amizade, solidariedade e justiça. Essas e outras tantas experiências têm como principal cenário as brincadeiras das crianças.

Ainda que a instituição escolar tenha se tornado o espaço por excelência para a convivência da criança com seus pares, a inserção de suas práticas lúdicas - produzidas neste contexto ou advindas de outros cenários, como a casa, a rua ou o parque - parece não se fazer sem contradições. As conceções de infância e de criança compartilhadas pela comunidade escolar - incluindo gestores(as), professores(as), funcionários(as), pais e mães - são determinantes para o acolhimento ou a negação das linguagens, valores, costumes, práticas corporais de seus estudantes, influenciando, em grande medida, as formas como os saberes são produzidos e partilhados no seio desta comunidade. Martins e Cruz (2014), preocupadas com a lógica adultocêntrica no contexto escolar, advertem para os modos escolares de organização das instituições, a fragmentação e o controle pelos adultos do tempo das crianças, assim como o seu confinamento em espaços cercados, fechados, artificializados, que limitam suas possibilidades do brincar em movimento e em grandes grupos.

É na sala de aula que as crianças permanecem a maior parte de seu tempo diário na escola. Embora os estudos sobre o valor do jogo e da brincadeira no contexto da sala de aula demonstrem a íntima relação e os benefícios da ludicidade no quadro das aprendizagens que fazem as crianças, sua cultura lúdica tem sido marginalizada, em grande escala, neste contexto, em nome de programas pedagógicos precisos que se baseiam no domínio de objetivos pré-estabelecidos, na ideia de crescer rápido e aprender ainda mais depressa, bem como na falta de envolvimento ativo das crianças nos processos de aprendizagem tendo como base conhecimentos, habilidades e entendimentos que elas trazem para esse processo (Brougère, 1998; Kishimoto, 2001; Moyles, 2006; Palma, 2008). Os cenários das salas de aula não nos deixam enganar: ao entrarmos nas salas de Escolas Maternais e Jardins de Infância, os ambientes parecem estar estruturados para que as crianças brinquem, mas, à medida que passamos às salas dos primeiros anos do Ensino Fundamental, paredes, mesas, prateleiras ficam carregadas de 
números, letras, trabalhos das crianças, etc. A essa altura, há provavelmente menos tempo diário consagrado aos seus jogos e brincadeiras do que nos anos anteriores. Compreendemos a importância da elaboração e da exposição dessas e de outras tarefas; questionamos é até que ponto elas revelam a preocupação dos adultos em relação ao futuro das crianças, sem Ihes permitir viver o seu presente de uma forma mais intensa.

A Educação Física, enquanto componente curricular obrigatória na Educação de Infância e nos anos iniciais do Ensino Fundamental (Brasil, 1996), pode e deve se configurar como um espaço e um tempo valiosos em que às crianças seja propiciada a oportunidade de expressar, partilhar e ressignificar suas culturas lúdicas, através de jogos, brincadeiras, danças, cantigas de roda, lutas, ginástica e esportes. Nessa perspetiva, autores como Neira (2008), Simão e Gomes-da-Silva (2008) e Freire e Goda (2008) enfatizam a importância do resgate das experiências e heranças culturais dos estudantes como ponto de partida nas aulas de Educação Física na escola, de tal forma que esses efetivamente participem da construção das mais distintas formas de conhecimento.

Considerando que as conceções sobre o jogo, o brinquedo e a brincadeira podem diferir consideravelmente entre pais, pesquisadores, professores e as próprias crianças (Glenn, Knight, Holt, \& Spence, 2012), queremos compreender as representações das crianças sobre o brincar em diferentes espaços escolares, nomeadamente o recreio, a sala de aula e a aula de Educação Física.

Sendo assim, este artigo está organizado em três seções: metodologia, análise de conteúdo e considerações finais, explicitando os caminhos por nós percorridos e as principais aprendizagens que construímos ao longo desta investigação.

\section{Metodologia do estudo}

Tendo em vista que o nosso foco de interesse se centrou na interpretação dos fenômenos a partir da perspetiva dos próprios participantes, optamos por uma investigação de cariz qualitativo, realizada em uma instituição escolar

A escolha da escola da rede estadual de ensino do Rio Grande do Sul, em Porto Alegre, se deu por conveniência e levou-se em consideração o fato 
de que esta instituição efetivamente oferecia aulas de Educação Física para todas as suas turmas, desde o Jardim de Infância ao $5^{\circ}$ ano do Ensino Fundamental. Sendo assim, foram agendadas e realizadas reuniões entre a pesquisadora e a direção da escola, bem como entre ela e os professores das turmas acima citadas, para a apresentação do objetivo, da metodologia e dos usos das informações construídas na pesquisa. Após a assinatura do Termo de Consentimento Institucional (TCI) pela direção, autorizando a realização da investigação em suas dependências, os pais/representantes legais receberam os Termos de Consentimento Livre e Esclarecido (TCLE) e muitos deles autorizaram a participação de seus filhos/protegidos legais através da assinatura do documento. Por fim, foram feitas reuniões (por turma) com as crianças cujos pais/representantes legais haviam autorizado a sua participação - também para apresentar o objetivo, a metodologia e os usos das informações construídas na pesquisa. As já alfabetizadas que aceitaram o convite assinaram o Termo de Assentimento (TA) e as não alfabetizadas expressaram verbalmente o seu desejo de participar ou não do estudo ${ }^{1}$.

Dessa forma, 106 crianças matriculadas em 11 turmas, do Jardim de Infância ao $5^{\circ}$ ano do Ensino Fundamental, com idades entre os 5 e os 12 anos, constituíram-se sujeitos desta pesquisa, a qual foi levada a cabo entre os meses de maio e dezembro de 2014.

$\mathrm{Na}$ tabela 1 são apresentados os níveis de ensino, os anos de escolaridade, os nomes das turmas e o respetivo número de crianças participantes. Cabe salientar que: (a) os Jardins de Infância (A e B) e o $1^{\circ}$ ano do Ensino Fundamental da escola eram constituídos por turmas únicas (daí a denominação JAU, JBU e $1 U$ ); e (b) embora houvesse três turmas de $2^{\circ}$ ano (turmas 21, 22 e 23), nenhum pai/representante legal da turma 21 autorizou a participação de seu filho/protegido legal no estudo.

Tabela 1 - Níveis de ensino, anos de escolaridade, nomes das turmas e número de crianças participantes

\begin{tabular}{|c|c|c|c|c|c|c|c|c|c|c|c|}
\hline \multirow{3}{*}{$\begin{array}{c}\begin{array}{c}\text { Níveis de } \\
\text { Ensino }\end{array} \\
\begin{array}{c}\text { Anos de } \\
\text { escolaridade }\end{array} \\
\text { Turmas }\end{array}$} & \multicolumn{2}{|c|}{$\begin{array}{c}\text { Educação de } \\
\text { Infância }\end{array}$} & \multicolumn{9}{|c|}{ Ensino Fundamental (anos iniciais) } \\
\hline & \multirow{2}{*}{$\begin{array}{c}\text { Jardim } \\
\text { A }\end{array}$} & \multirow{2}{*}{$\begin{array}{c}\begin{array}{c}\text { Jardim } \\
\text { B }\end{array} \\
\text { JBU }\end{array}$} & \multirow{2}{*}{$\frac{1^{\circ} \mathrm{ano}}{1 \mathrm{U}}$} & \multicolumn{2}{|c|}{$2^{\circ}$ ano } & \multicolumn{2}{|c|}{$3^{\circ}$ ano } & \multicolumn{2}{|c|}{$4^{\circ}$ ano } & \multicolumn{2}{|c|}{$5^{\circ}$ ano } \\
\hline & & & & 22 & 23 & 31 & 32 & 41 & 42 & 51 & 52 \\
\hline $\mathrm{N}$ & 5 & 11 & 12 & 7 & 10 & 8 & 13 & 16 & 8 & 4 & 12 \\
\hline
\end{tabular}


A técnica de recolha de dados foi o inquérito por entrevista semiestruturada, para permitir a escuta das vozes das crianças. A entrevista foi aplicada primeiramente de forma individual e, posteriormente, de forma coletiva (por turma), a qual denominamos roda de conversa. Os roteiros contemplaram aspetos relacionados às culturas lúdicas das crianças tanto em contexto escolar como extraescolar; entretanto, neste artigo daremos prioridade à análise das representações que elas fazem sobre as culturas lúdicas em espaços escolares.

Todas as entrevistas foram audiogravadas e transcritas pela própria pesquisadora; a técnica utilizada para a análise das informações constituiu-se na análise de conteúdo (Bardin, 2011). Em meio às recorrências e às singularidades das falas das crianças, identificamos algumas temáticas de estudo: (a) as brincadeiras preferidas; (b) o recreio e os pátios como o tempo e os espaços da escola para brincar; (c) o brincar na sala de aula; e (d) o brincar nas aulas de Educação Física. No intuito de preservar a identidade das crianças participantes da pesquisa, utilizamos nomenclaturas fictícias; para exemplificar: $\mathrm{C} 1132$ = criança 11 da turma 32

\section{Resultados}

Iniciamos nossas conversas com as crianças sugerindo-lhes que nos contassem sobre suas brincadeiras preferidas, por que essas eram assim consideradas, quando e onde eram realizadas e tudo o mais que quisessem falar a esse respeito.

\section{As brincadeiras preferidas}

A grande maioria das crianças de cada uma das turmas - desde as do Jardim $A$ até as do $5^{\circ}$ ano - mencionou brincadeiras que implicavam movimento e realizadas em grandes grupos como as suas prediletas. Pegapega, jogar bola, pular corda, polícia e ladrão e esconde-esconde foram as mais citadas pelas crianças, sendo os motivos para isso o fato de serem divertidas, poderem realizá-las com os amigos e poderem correr. O recreio foi o tempo e os pátios da escola os espaços onde dizem brincar do que mais gostam. Nossos achados são similares aos de estudos prévios (Glenn et al., 2012; Miller \& Kuhaneck, 2008), em que as crianças relacionaram suas 
brincadeiras preferidas a atividades com grande movimentação corporal. O envolvimento ativo e vigoroso das crianças na exploração e na experimentação das suas capacidades motoras é característico das culturas da infância, representando uma necessidade, não só para as crianças pequenas, em idade pré-escolar, como também para as que já ingressaram na escola de Ensino Fundamental. Para ilustrar essa afirmação, basta que dediquemos alguns minutos a observar o recreio escolar, espaço em que, via de regra, crianças de diferentes idades podem escolher suas atividades e, na grande maioria das vezes, optam pelas dinâmicas e intensas, utilizando-se de habilidades como correr, pular, equilibrar-se, arremessar e apanhar bolas para se divertir, o que pôde ser constatado na fala de $\mathrm{C}_{031 \mathrm{u}}$ : "Porque eu sou muito bom no pega-pega e consigo correr muito rápido".

A diversão foi outro motivo apontado com frequência pelas crianças como distintivo das suas brincadeiras preferidas: "Esconde-esconde, porque é muito divertido" $\left(\mathrm{C}_{0832}\right)$. Também na percepção dos estudantes investigados por Berinstein e Magalhães (2009) e Glenn et al. (2012), a diversão era a condição para que uma atividade se caracterizasse como brincadeira e, inversamente, uma atividade chata não poderia ser considerada como tal. Em nossa prática pedagógica cotidiana, deparamo-nos com crianças quase sem fôlego e no limite de suas capacidades, correndo para não serem pegas em brincadeiras como, por exemplo, polícia e ladrão, mas com um enorme sorriso no rosto; acreditamos que o prazer e o divertimento que emanam dessas e de outras atividades são a causa de tamanha entrega e a mola propulsora para o envolvimento das crianças; daí, concordarmos com Brougère (1998), ao referir que o brincar não é um comportamento específico, mas uma situação na qual esse comportamento adquire uma significação específica.

Estar e brincar com os pares é algo importante na vida das crianças; nesta investigação, algumas mencionaram preferir as brincadeiras que podiam realizar com seus amigos ou irmãos, em suas casas ou próximo a estas, como no pátio e na rua, mas a grande maioria apontou que as brincadeiras prediletas o são porque as realizam com os amigos da (e na) escola. $\mathrm{C}_{08 \mathrm{JBU}}$ expressou: "Eu adoro pular corda aqui, porque daí todos os amigos podem brincar junto". Com muita propriedade, Silva (2011) adverte para as mudanças que vêm ocorrendo nas culturas lúdicas da infância ao longo das últimas décadas, em que jogos e brincadeiras partilhados por 
crianças em grupo, com interação cara a cara com irmãos, vizinhos, amigos e companheiros de escola e realizados maioritariamente nos espaços externos às casas, têm sido substituídos por formas solitárias de jogo, com interações diferidas - prioritariamente à frente de objetos portadores de novas tecnologias, como os jogos de vídeo, a televisão, os tablets, etc. -, no interior de suas casas. Por esses e tantos outros motivos, pensamos ser hoje a escola a instituição que melhor pode promover a interação entre as crianças, propiciando-Ihes a oportunidade de expressarem e compartilharem os traços das culturas que trazem consigo, especialmente os da sua cultura lúdica, para, no contexto escolar, fazerem emergir novas e/ou ressignificadas culturas.

\section{O recreio e os pátios como o tempo e os espaços da escola para} brincar

É admirável que esses quinze a vinte minutos, num universo de 24 horas diárias, representem um tempo tão precioso, tão mágico para as crianças! É nesse pequenino tempo que elas dizem fazer o que mais gostam: brincar! E, brincando, estão com os amigos, divertem-se, correm, negociam regras, transgridem-nas, resolvem conflitos, partilham coisas, pensamentos e sentimentos, fazem amizades, exploram os brinquedos, aprendem novas brincadeiras e ensinam-nas aos pares, fazem descobertas incríveis sobre o espaço à sua volta, caminham e conversam com os(as) melhores amigos(as), representam e são, por pouco tempo que Ihes caiba, um grande jogador de futebol, o equilibrista do circo, a mamãe e a filhinha, o policial ágil, o dinossauro, a professora de inglês e outros tantos personagens que a imaginação Ihes permitir. Essas foram algumas das tantas ideias confidenciadas pelas crianças deste estudo, ao falarem sobre como é o recreio na escola em que estudam.

Pudemos constatar nas falas das crianças a presença frequente de conflitos provenientes dos estereótipos de gênero nas brincadeiras, como disseram $\mathrm{C}_{1023}$ : "a gente não deixa os meninos brincarem, porque eles ficam empurrando; daí a gente tenta tirar eles das brincadeiras e eles não saem. Quando eles saem, as gurias dizem: 'ai, que livre que eu fiquei deles!'” e $\mathrm{C}_{0432}$ : "todo mundo tinha que brincar junto, mas eles começam a falar dos defeitos das gurias, as gurias começam a falar dos deles, e aí a gente se 
separa". Ainda, para ilustrar a transgressão às regras estipuladas pela escola e, ao mesmo tempo, a necessidade que as crianças maiores têm de brincar com brinquedos, concebidos pelos adultos como para os pequenos, $\mathrm{C}_{0352}$ conta-nos: "De vez em quando eu e meus colegas vamos para o pátio dos pequenos, porque lá é legal, dá para brincar na pracinha... mas não pode, é só para os pequenos".

Para algumas (ou muitas) crianças o recreio é a única - ou uma das poucas - oportunidade(s) em que podem brincar em integração umas com as outras, com adultos menos invasivos, mesmo que com supervisão permanente. Esse contexto parece Ihes propiciar a autonomia e a independência de que tanto necessitam para, enquanto sujeitos de direito à participação, exercerem a capacidade de se auto-organizar, constituírem-se como grupos e criarem redes de práticas sociais, nas quais seus jogos e brincadeiras são algumas das mais importantes formas de perpetuação e produção das culturas da infância.

Os pátios foram mencionados quase que unanimemente pelas crianças como os melhores espaços da escola para brincar, porque: (a) são grandes e possibilitam a realização das brincadeiras preferidas $\left(\mathrm{C}_{0142}\right.$ : "No pátio, porque é maior e dá pra fazer as brincadeiras mais legais, tipo jogar bola, pega-pega..."); (b) têm brinquedos ( $\mathrm{C}_{03 \mathrm{JAU}}$ : " No pátio, porque dá pra ir no escorregador e na pracinha"); e (c) porque muita gente pode brincar junto $\left(\mathrm{C}_{101 \mathrm{U}}\right.$ : "Porque lá [referindo-se ao pátio] é grande e todo mundo brinca junto de muitas coisas").

Ao escutarmos e refletirmos sobre a riqueza das experiências partilhadas nesses relatos, não podemos deixar de registrar aqui a nossa concordância com as preocupações de Azevedo (2014) quanto à insuficiência de tempo e de espaço disponibilizados às crianças em seus cotidianos para brincarem e, em especial, para brincarem com seus pares. Temos cada vez mais crianças enclausuradas em casa, e mesmo na escola, limitadas a compartilhar escassos minutos do seu dia com seus companheiros de brincadeiras, quando, na realidade, dever-Ihes-ia ser garantido o seu direito de brincar em grande parte da sua infância. 


\section{O brincar na sala de aula}

Ao falarem sobre brincadeiras na sala de aula, as crianças das turmas de Jardim de Infância e as do Ensino Fundamental expressaram realidades bastante distintas em relação a essa temática. Todos os participantes matriculados nas turmas de Jardim A e Jardim B disseram brincar em sua sala de aula e deram inúmeros exemplos das brincadeiras ali realizadas, como de bonecas, carrinhos, quebra-cabeças, maquiagem, de mentirinha (referindo-se ao faz-de-conta), de castelo, de monstro, etc. Afirmaram ainda que normalmente eles próprios escolhem as brincadeiras e outras vezes são as professoras a escolher.

Entretanto, para as crianças do Ensino Fundamental (já a partir do $1^{\circ}$ ano), o tempo de estudar/aprender e o tempo de brincar aparecem muito bem demarcados nas suas falas. A grande maioria relata não brincar na sala de aula, porque tem de estudar, como se pode verificar nas palavras de $\mathrm{C}_{0332}$ : "Porque é tão óbvio, né?! Não pode; sala de aula é pra aprender, não pra brincar". Muitos outros referem que não brincam porque a professora não deixa: "A gente não pode brincar; tem que estudar, senão a profe nos deixa de castigo, sem pátio" $\left(C_{121 \cup}\right)$. Alguns ainda relacionaram o fato de não brincarem em sala com não haver espaço para isso: "Imagina! Não tem como brincar na sala, ela é pequena. Já pensou se eu jogo futebol na sala de aula?" $\left(\mathrm{C}_{0642}\right)$.

Durante as rodas de conversa, foi possível constatar que algumas situações caracterizaram-se, para algumas das crianças, como brincadeiras, ainda que, para a maioria, não: (a) 'brincar' com os jogos disponibilizados pelas professoras, como os de matemática, xadrez, dominó, etc; (b) 'brincar' de desenhar, ou jogar forca ou outro jogo calmo, permanecendo sentados, depois de terminarem as tarefas escolares; (c) 'brincar' na sala durante o recreio, quando chove; e (d) foram relatadas algumas brincadeiras realizadas sem a permissão das professoras, como nos contaram $\mathrm{C}_{0323}$ : "A gente brinca escondido da profe; quando ela sai, a gente vai lá pra frente e fica pulando" e $\mathrm{C}_{0251}$ : "A profe não vê, mas a gente brinca de colocar bolinha de papel na caneta e atirar nos outros...".

Fica-nos claro, a partir das vozes das crianças dos Jardins de Infância, que o brincar é promovido e incentivado pelas professoras nas respetivas salas, diferentemente do que nos disseram as crianças de $1^{\circ}$ a $5^{\circ}$ ano do 
Ensino Fundamental, em cujas salas a ludicidade parece estar totalmente desvinculada das aprendizagens. Nessa perspetiva, Sarmento (2011) expressa que o universo simbólico dos alunos - seus jogos, rituais, a própria linguagem gerada nas relações de pares e configurantes das culturas juvenis e culturas de infância - muitas vezes é ignorado pela escola, alertando para o fato de que as crianças não se constituem sujeitos do conhecimento apenas pela assimilação de conteúdos educativos; para o autor, fazer-se sujeito do conhecimento abrange outros domínios, percorre outros conteúdos, potencia outros modos de comunicar, exprime-se noutras linguagens que, amiúde, são alheias ao controle e mesmo à compreensão dos adultos.

Numa sociedade cada vez mais focada no progresso econômico, as crianças parecem estar sendo impelidas, desde muito cedo, a trilhar caminhos de obrigações, investimentos, responsabilidades, sucesso, através de conteúdos e práticas escolarizantes que projetam nesses seres em formação um futuro ao qual não pertencem, negando-lhes a oportunidade de viverem intensamente o presente e desrespeitando-lhes a condição de serem crianças hoje.

Cabe-nos, ainda, refletir sobre duas questões interessantes apontadas pelas crianças. A primeira diz respeito ao fato de os jogos propostos em sala de aula pelas professoras serem, ou não, considerados pelas crianças como jogos/brincadeiras. Sabemos que as conceções de jogo/brincadeira podem variar de cultura para cultura, de época para época, entre pessoas de uma mesma cultura e época, de adulto para criança, ou, ainda, entre crianças. Para Romera et al. (2007), "o brinquedo não pode perder sua magia enquanto exerce função educativa, pois a partir do momento em que deixa de provocar prazer e alegria em detrimento da aprendizagem, deixa de ser brinquedo e passa a ser tão somente material pedagógico" (p. 140). Assim, os jogos relatados por alguns participantes do nosso estudo foram percebidos como brincadeiras, enquanto que, para seus colegas, essas atividades assumiam outros significados, desvinculados dos que esperam encontrar enquanto brincam ou jogam.

A segunda questão refere-se à transgressão da ordem, nomeadamente à proibição da realização de brincadeiras na sala de aula. Corsaro (2011) argumenta que o desafio à autoridade adulta é um recurso universal das culturas da infância e representa o desejo das crianças em 
conquistar autonomia e obter o controle sobre suas vidas, especialmente em relação às regras e aos limites impostos pelos adultos e, ao mesmo tempo, é uma ferramenta utilizada para a formação de sua identidade grupal, daí ser tão atraente para elas. O que fica evidente, a partir das falas de algumas de nossas crianças, é que, apesar das normas que restringem e/ou proíbem suas brincadeiras em sala, elas subvertem a ordem e brincam.

\section{O brincar nas aulas de Educação Física}

Pega-pega, jogar bola, pular corda, caçador, amarelinha, escondeesconde, futebol, chefe manda são algumas das várias brincadeiras que as crianças dizem realizar em suas aulas de Educação Física. Embora o futebol tenha sido referido por alguns alunos, desde o Jardim de Infância, como uma das brincadeiras realizadas nessas aulas, outras modalidades esportivas, como o voleibol e o basquetebol, também foram bastante citadas pelos estudantes a partir do $3^{\circ}$ ano. A grande maioria dessas atividades coincide com as que as crianças dizem ser as suas preferidas e, ainda, as que praticam durante o recreio.

Julgamos interessante o fato de as crianças (em todas as turmas) manifestarem que praticam muitas atividades diferentes na Educação Física ao longo do ano; acreditamos fortemente que esse período da infância seja o momento de elas experimentarem vivências diversificadas no mundo da atividade física, tendo a oportunidade de conhecer, partilhar e criar linguagens próprias de movimento e, como nos diz Sayão (2000), "ampliar seus conhecimentos em inúmeras dimensões, como a ética, estética, corporal, mimética, sensível, oral, escrita, artística, rítmica, entre outras" (p. 37). É na descoberta e no encontro de muitas dessas linguagens - seja nos jogos, nas brincadeiras, nos esportes, etc. - que as crianças se expressam e, aos poucos, vão-se integrando e constituindo suas culturas de pares.

Muitas são as "lentes" através das quais poderíamos buscar compreender o que dizem nossos participantes sobre suas brincadeiras nas aulas de Educação Física. Chamou-nos a atenção o fato de que as brincadeiras preferidas das crianças são, quase unanimemente, as que repetidamente realizam nas aulas de Educação Física e também no recreio; imediatamente, então, confrontamo-nos com o conceito de reiteração, 
proposto por Sarmento (2003). A reiteração configura-se como um dos quatro pilares (juntamente com a interatividade, a ludicidade e a fantasia do real) que estruturam as culturas de infância e se caracteriza como uma oportunidade ímpar que o brincar oferece ao brincante de poder fazer outra vez, e de novo, e quantas vezes forem necessárias para explorar até a exaustão os mesmos ou renovados papéis, situações ou rituais. Nessas experiências reproduzidas, muitas vezes as crianças escolhem para brincar parceiros com quem o fazem habitualmente, porque dão continuidade às brincadeiras, ainda que os objetos possam assumir diferentes significados, as crianças possam desempenhar diferentes papéis, sejam introduzidas novas ações e, através dessa incessante recriação de situações e rotinas, cada criança, à sua maneira e ao seu tempo, vai dominando e compartilhando os recursos, as linguagens, os códigos e os rituais, passando de geração para geração sua cultura lúdica e, como afirma Benjamin (1992), vai, paulatina e reiteradamente, construindo a sua arte de lidar com o mundo.

Nesse sentido, o brincar, em suas múltiplas formas de manifestação, pode ser o elemento desencadeador de ricas fontes de conhecimento e de (re)produção de cultura, através da interação entre as crianças e entre elas e os adultos. É importante frisar, entretanto, que, por geralmente não se apropriarem nem compartilharem os códigos e as linguagens das crianças, os adultos acabam por não compreender o prazer das repetidas e continuadas brincadeiras, réplicas umas das outras, praticadas pelos infantes.

\section{Considerações finais}

A partir da escuta das vozes das crianças participantes nesta investigação, foi-nos possibilitada a compreensão de suas perspetivas relativamente ao universo lúdico que criam, recriam e partilham cotidianamente no cenário da escola. Utilizando-se de diferentes recursos linguísticos, apontaram as brincadeiras com ampla movimentação corporal e realizadas em grandes grupos como as suas prediletas, pelo fato de serem divertidas, poderem desempenhá-las com os amigos e poderem correr. Além disso, referiram o recreio como o tempo e os pátios da escola como os espaços onde brincam do que mais gostam, porque neles os ambientes são amplos, há brinquedos e podem estar junto dos colegas. 
No que se refere às brincadeiras em sala de aula, constataram-se diferenças quanto às representações das crianças que frequentam Jardins de Infância e as dos anos iniciais do Ensino Fundamental ( $1^{\circ}$ ao $5^{\circ}$ ano): enquanto as mais novas afirmam brincar neste espaço, as mais velhas declaram não brincar ou brincar pouco em sala, muitas vezes expressando a sua concordância ou discordância em realizar brincadeiras num espaço supostamente destinado somente à aprendizagem.

As falas das crianças sobre as aulas de Educação Física permitem-nos reconhecer nessa componente curricular a oportunidade de elas vivenciarem brincadeiras diversificadas no mundo da atividade física, muitas das quais coincidem com as suas preferidas e as que praticam durante o recreio.

A partir das interpretações dos respetivos mundos de vida, os participantes deste estudo proporcionaram-nos um olhar mais profundo sobre o cotidiano escolar e as culturas lúdicas que emergem e se desenvolvem nos diferentes tempos e espaços desta instituição. O brincar fisicamente exuberante, o brincar proibido, o brincar em grupo, o brincar sob conflitos, o brincar que promove ou que atrapalha aprendizagens: eis algumas das muitas facetas de um fenômeno que arrebata crianças de todo o mundo e que dá sentido às suas vidas.

Já é tempo de refletirmos sobre o que nossas crianças têm a dizer sobre tudo o que lhes diz respeito; desde muito pequenas, através das inúmeras experiências por que passam, tornam-se sujeitos capazes de construir e de expressar representações acerca de si, dos pares, dos adultos e das instituições que os acolhem. Enquanto educadores, torna-se fundamental conhecermos e, mais do que isso, considerarmos os seus pontos de vista, as suas expectativas e as suas necessidades, de forma a incluí-los como partícipes na produção de conhecimentos, especialmente aqueles que os afetam diretamente. E, em se tratando das culturas lúdicas da infância, as crianças têm muito a nos dizer e muito a nos ensinar.

\section{Nota}

1 Todos os Termos (TCI, TCLE, TA) e o projeto desta pesquisa foram aprovados pelo Comitê de Ética em Pesquisa da Universidade Federal do Rio Grande do Sul (CAEE:32198614.7.0000.5347). 


\section{Referências}

Azevedo, O. (2014). Chegou a hora do recreio! O recreio: Espaço de construção de culturas de infância (Dissertação de Mestrado). Universidade do Minho, Braga.

Bardin, L. (2011). Análise de conteúdo. São Paulo: Edições 70.

Belloni, M. (2007). Infância, mídias e educação: Revisitando o conceito de socialização. Perspectiva, 25(1),57-82.

Benjamin, W. (1992). Sobre arte, técnica, linguagem e política. Lisboa: Relógio d'Água.

Berinstein, S., \& Magalhães, S. (2009). A study of the essence of play experience to children living in Zanzibar, Tanzania. Occupational Therapy International, 16(2), 89-106. doi: 10.1002/oti.270

Brougère, G. (1998). Jogo e educação. Porto Alegre: Artes Médicas.

Corsaro, W. (2011). Sociologia da infância. Porto Alegre: Artmed.

Freire, J., \& Goda, C. (2008). Fabrincando: As oficinas do jogo como proposta educacional nas séries iniciais do Ensino Fundamental. Movimento, 14(1), 111-134.

Glenn, N., Knight, C., Holt, N., \& Spence, J. (2012). Meanings of play among children. Childhood, 20(2), 185-199. doi: 10.1177/0907568212454751

Kishimoto, T. (2001). A LDB e as instituições de educação infantil: desafios e perspectivas. Revista Paulista de Educação Física, supl.4, 7-14.

Kishimoto, T. (2010). Jogo, brinquedo, brincadeira e a educação (13 ${ }^{\mathrm{a}}$ ed.). São Paulo: Cortez.

Martins, I., \& Cruz, M. (2014). Brincar na rua e brincar na escola: Infância, lazer e educação. Impulso, 24(61), 17-30. doi: 10.15600/2236-9767

Miller, E., \& Kuhaneck, H. (2008). Children's perceptions of play experiences and play preferences: A qualitative study. The American Journal of Occupation Therapy, 62(4), 407-415.

Moyles, J. (2006). A excelência do brincar. Porto Alegre: Artmed.

Nascimento, A., \& Souza, K. (2014). Por uma antropologia da infância: Pesquisando o recreio. Cadernos de Pesquisa, 44(152), 466-469. doi: 10.1590/198053142840

Neira, M. (2008). A cultura corporal popular como conteúdo do currículo multicultural da Educação Física. Pensar a prática, 11(1), 81-89. doi: 10.5216/rpp.v11i1.1699

Palma, M. (2008). O desenvolvimento de habilidades motoras e o engajamento de crianças pré-escolares em diferentes contextos de jogo (Tese de Doutoramento). Universidade do Minho, Braga.

Palma, M., Almeida, B., Turcati, V., \& Pontes, M. (2015). Jogos tradicionais no contexto educativo. Kinesis, 33(2), 99-113. doi: 105902/0102830817402

Romera, L., Russo, C., Bueno, R., Padovani, A., Silva, A., Silva, C., ...Silva, P. (2007). O lúdico no processo pedagógico da educação infantil: Importante, porém ausente. Movimento, 13(2),131-152.

Sarmento, M. (2003). Imaginário e culturas da infância. Cadernos de Educação, 21, 51-69.

Sarmento, M. (2004). As culturas da infância nas encruzilhadas da $2^{a}$ modernidade. In M. Sarmento \& A. Cerisara (Orgs.), Crianças e miúdos. Perspectivas sóciopedagógicas da infância e educação (pp. 9-34). Porto: Asa. 
Sarmento, M. (2008). Sociologia da infância: Corrente e confluências. In M. Sarmento \& M. Gouvea (Orgs.), Estudos da infância: Educação e práticas sociais (pp. 1739). Petrópolis: Vozes.

Sarmento, M. (2011). A reinvenção do ofício de criança e de aluno. Atos de Pesquisa em Educação, 6(3), 581-602. doi: 10.7867/1809-0354

Sarmento, M., \& Marchi, R. (2008). Radicalização da infância na segunda modernidade: Para uma sociologia da infância crítica. Configurações, 4. Disponível em: $<$ https://configuracoes.revues.org/498>

Sarmento, M., Fernandes, N., \& Tomás, C. (2007). Políticas públicas e participação infantil. Educação, Sociedade \& Culturas, 25, 183-206.

Sayão, D. (2000). Infância, Educação Física e Educação Infantil. In Secretaria Municipal da Educação, Síntese da qualificação da Educação Infantil (pp. 36-41). Florianópolis: Secretaria Municipal de Educação.

Silva, A. (2008). Crianças, escola, recreação e lazer: Uma relação inquietante. In B. Pereira, A. Silva, \& G. Carvalho (Orgs.), Atividade física, saúde e lazer: O valor formativo do jogo e da brincadeira (pp. 11-26). Braga: Universidade do Minho.

Silva, A. (2011). Jogos, brinquedos e brincadeiras: Trajectos intergeracionais: Vila Verde: ATAHCA.

Simão, M., \& Gomes-da-Silva, E. (2008). Pesquisa com crianças na Educação Física: Questões teóricas e desafios metodológicos. Inter-Ação, 33(2), 395-416. doi: 10.5007/1980-4512.2010n21p12

Valença, V. (2010). A sociologia da infância e a educação das crianças. Inter-Ação, 35(1), 63-80. doi: 10.5216/ia.v35i1.13144

\section{Legislação consultada}

Brasil (1990). Estatuto da Criança e do Adolescente. Brasília: Edições Câmara.

Brasil (1996). Lei no 9.394, de 20 de dezembro de 1996. Lei de Diretrizes e Bases da Educação Nacional. Disponível em: http://www.planalto.gov.br/ccivil_ 03/Leis/L9394.htm

Comitê sobre os Direitos da Criança (2013). General comment $n^{\circ} 17$ on the right of the child to rest, leisure, play, recreational activities, cultural life and the arts (art. 31). United Nations - Convention on the Rights of the Child. Disponível em: http://www2.ohchr.org/english/bodies/ crc/docs/GC/CRC-C-GC-17_en.doc

UNICEF (1959). Declaração Universal dos Direitos das Crianças. Disponível em: http://bvsms.saude.gov.br/bvs/publicacoes/declaracao_universal_direitos_ crianca.pdf

UNICEF (1989). A Convenção sobre os Direitos da Criança. Disponível em: http://www.unicef.pt/docs/pdf_publicacoes/convencao_direitos_ crianca2004.pdf 


\section{CHILDRENS' REPRESENTATIONS ABOUT PLAYING AT SCHOOL}

\section{Abstract}

The purpose of this study was to understand children's representations about playing in different spaces at school, namely in the playground, in the classroom and in Physical Education class. From the analysis of the interviews with 106 children, aged between 5-12, who attended a public school in Porto Alegre, Rio Grande do Sul, Brazil, we verified that their favorite games were those which demanded body movement and were played in big groups during recess in the playground. Kindergarden children stated that they play in their classrooms, while Elementary School children said they don't play or play very little in their classrooms. Children play diverse games in Physical Education classes, many of which coincide with their favorite ones.

Keywords

Childhood; Play; Education

\section{REPRESENTACIONES DE LOS NIÑOS SOBRE EL JUGAR EN LA ESCUELA}

\section{Resumen}

El objetivo de esta investigación fue comprender las representaciones de los niños acerca del jugar en diferentes espacios escolares, a saber, en el patio de recreo, en el aula y en la clase de Educación Física. A partir del análisis de las entrevistas realizadas con 106 niños, entre 5 y 12 años de edad, en una escuela de la red pública de educación en Porto Alegre, Rio Grande do Sul, Brasil, se verificó que sus juegos preferidos son aquellos que implican movimientos corporales y se realizan en grupos grandes, los cuales ocurren durante el recreo en los patios de la escuela. Los niños que frecuentan la Educación Infantil afirmaron que juegan en el aula, mientras los de Educación Primaria declararon no jugar o jugar poco en ese espacio. En las clases de 
Educación Física, ellos realizan diversos juegos, muchos de los cuales coinciden con sus favoritos.

Palabras-clave

Infancia; Juegos; Educación

Recebido em agosto 2016 Aceite para publicação em maio 2017

i Escola de Educação Física, Fisioterapia e Dança, Universidade Federal do Rio Grande do Sul, Brasil

Toda a correspondência relativa a este artigo deve ser enviada para: Míriam Stock Palma, Rua Honório Silveira Dias, 1529 ap.402, Porto Alegre, RS, Brasil CEP: 90540-070. E-mail: miriam.palma@ufrgs.br 